\title{
Enabling The Disabled Through Educational Amenities: A Sociological Analysis On Maheshwari School For Blind
}

\author{
Ziya A. Pathan \\ (Head of Department, Al-Ameen College, Belgaum, Karnataka, India)
}

\begin{abstract}
Education is the foundation of the entire structure of the nation as it is not concerned with any group or class, but has a direct influence on the entire population of the country. Education is an important factor in creating social order and is founded on certain essential values. Education of exceptional children is a challenging field.

A disability is any restriction or lack of ability to perform an activity in a manner or within the range considered normal for a human being, resulting from any impairment. Disability comes in many forms like hearing, visual, orthopedic, mental and learning.
\end{abstract}

\section{Meaning and Definition:}

Blindness is the condition of lacking visual perception due to physiological or neurological factors. Total blindness is the complete lack of form and visual light perception and is clinically recorded as NLP, an abbreviation for "No light perception". Blindness is frequently used to describe, severe visual impairment with residual vision. Those described as having only light perception have no more sight than the ability to tell light from dark and the general direction of a light source.

Childhood blindness refers to a group of diseases and conditions occurring in childhood or early adolescence, which if left untreated results in blindness or visual impairment, that are likely to be untreatable later.

According to Ashcroft "Blind pupils as those who have so little remaining vision that they must use Braille as their reading medium"

In North America and most of Europe, legal blindness is defined as visual acuity (vision) of 20/200(6/60) or less in the better eye with best correction possible.

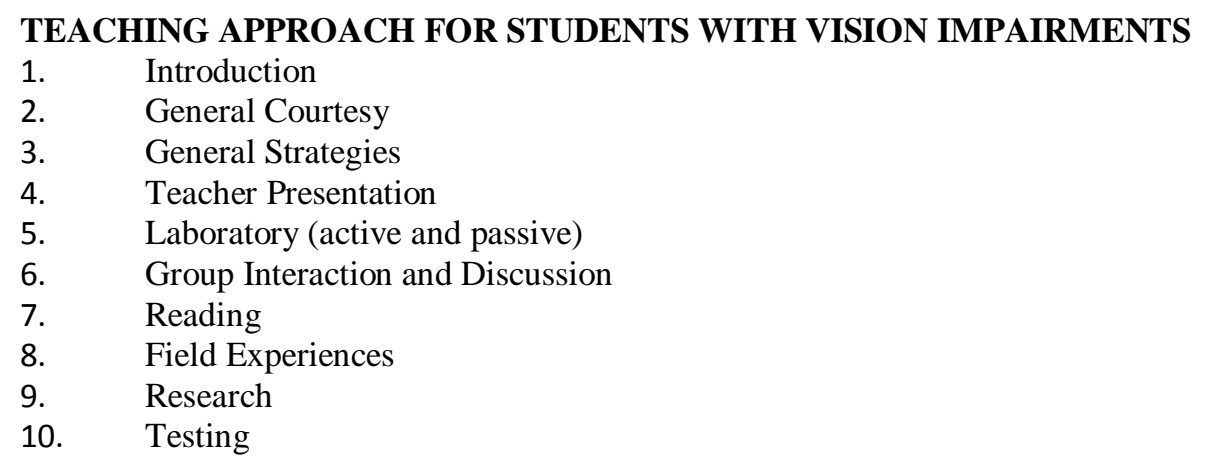

\section{Introduction:}

There are two main categories of visual impairments: Low Vision and Blind. Low vision students usually are print users, but may require special equipment and materials. The definition of legal blindness covers a broad spectrum of visual impairments. The extent of visual disability depends upon the physical sensory impairment of the student's eyes, the age of the student at the onset of vision impairment, and the way in which that impairment occurred. Vision also may fluctuate or may be influenced by factors such as inappropriate lighting, light glare, or fatigue. Hence, there is no "typical" vision impaired student. The major challenge facing visually impaired students in the educational environment is the overwhelming mass of visual material to which they are continually exposed in textbooks, class outlines, class schedules, chalkboards writing, etc. In addition, the increase in the use of films, videotapes, computers, laser disks, and television adds to the volume of visual material to which they have only limited access. Overcoming a student's visual limitation requires unique and individual strategies based on that student's particular visual impairment and his/her skill of communication (e.g., Braille, speed listening, etc.). (After: "The Mainstream Teaching of Science: A Source Book", Keller et al.) 
General Courtesy

1. Speak to the class upon entering and leaving the room or site.

2. Call the student by name if you want his/her attention.

3. Use descriptive words such as straight, forward, left, etc. in relation to the student's body orientation. Be specific in directions and avoid the use of vague terms with unusable information, such as "over there", "here", "this", etc.

4. Describe, in detail, pertinent visual occurrences of the learning activities.

5. Describe and tactually familiarize the student to the classroom, laboratory, equipment, supplies, materials, field sites, etc.

6. Give verbal notice of room changes, special meetings, or assignments.

7. Offer to read written information for a person with a visual impairment, when appropriate.

8. Identify yourself by name, don't assume that the student who is visually impaired will recognize you by your voice even though you have met before.

9. If you are asked to guide a student with a visual impairment, identify yourself, offer your services and, if accepted, offer your arm to the student's hand. Tell them if they have to step up or step down, let them know if the door is to their left or right, and warn them of possible hazards. Orally, let the student know if you need to move or need to end a conversation.

10. If a visually impaired student is in class, routinely check the instructional environment to be sure it is adequate and ready for use.

11. When communicating with a student who has a vision impairment, always identify yourself and others who are present.

12. Do not pet or touch a guide dog. Guide dogs are working animals. It can be hazardous for the visually impaired person if the dog is distracted.

13. Be understanding of the slight noise made by a portable brailler.

14. Also use an auditory or tactile signal where a visual signal is normally used.

15. It is not necessary to speak loudly to people with visual impairments.

\section{General Strategies}

The various strategies given below will work for most vision impaired students -some will not. The degree of impairment and the student's background and training (like the degree of proficiency in Braille) will affect the usefulness of the various strategies and suggestions. The student with a vision impairment will most likely need assistance in accessing instructional materials, taking notes, and/or taking tests. Accessible description will be necessary for pictures, graphics, or displays; the student's identification queries; and differentiation of items where touch will not discriminate; and in orientation and mobility aspects in unfamiliar situations.

1. Bring to the student's attention to assist persons in reading or working with objects that need to be observed

2. A screen reader or an item like out SPOKEN can be used to read a computer screen to a visually impaired student.

\section{Teacher Presentation:}

1. By verbally spelling out a new or technical word, you will be helping the visually impaired student, as well as for other students.

2. An enlarged activity script, directions, or readings of a detailed lesson can be used for a low vision person and for use in describing tactile 3D models.

3. Use an overhead projector to show step-by-step instructions. Mask all the instructions except the one(s) that you want followed.

4. Use an opaque projector whenever possible to enlarge a text or manual.

5. All colored objects used for identification related to a lesson, experiment, or other directions should be labeled with a braille label maker or otherwise coded.

6. Describe, in detail, visual occurrences, visual media, and directions including all pertinent aspects that involve sight.

7. Use a sighted narrator or descriptive video to describe aspects of videos or laser disks.

8. Describe, in detail, all pertinent visual occurrences or chalkboard writing.

9. Where needed, have lesson or direction materials Brailed, or use an enlarged activity script ahead of time, for class handouts.

10. Have tactile 3D models, raised line drawings, or thermoforms available to supplement drawings or graphics in a tactile format when needed.

11. Whenever possible, use actual objects for three dimensional representations.

12. Modify instructions for auditory/tactile presentation.

13. Use raised line drawings for temporary tactile presentations. 
14. Use an overhead projector, chalkboard, graphs, or slides as you would normally, but provide more detailed oral descriptions, supplemented with thermoforms where appropriate.

15. Allow student to use a tape recorder for recording class presentations.

16. Make all handouts and assignments available in an appropriate form: e.g., regular print, large print, Braille, or cassette, depending on the student's optimal mode of communication.

17. Use a monocular or a private eye (electronic miniature television) for long range observations of chalk board or demonstration table presentations.

\section{Laboratory}

1. Describe and tactually/spatially familiarize the student with the lab and all equipment to be used.

2. Consider alternate activities/exercises that can be utilized with less difficulty for the student, but has the same or similar learning objectives.

3. Use an enlarged activity script, directions, or readings for a low vision student (or taped script for a student who is Blind) for use with tactile 3D models.

4. Make all handouts and assignments available in the appropriate form for the student: e.g., regular print, large print, Braille, or tape depending on the student's optimal mode of communication.

5. Assistance from a special education teacher may be needed for converting laboratory materials from a visual to a tactile format.

6. Have the student with a vision impairment do a trial run on the equipment before the activity.

7. Allow more time for the laboratory activities.

8. Always try to keep materials, supplies, and equipment in the same places.

9. Use a micro-projector to help the visually impaired student to examine images from a microscope.

10. Place the student and/or tape recorder an appropriate distance from the activity to permit hearing and/or the recording of results or observations.

11. Use an overhead projector or opaque projector to show step-by-step instructions. Mask all the instructions except the one(s) that you want followed for students with vision impairments.

12. Use Descriptive Video for videos or laser disks. If Descriptive Video is not available, use a sighted narrator to describe movies, videos, laser disks, or slides.

13. Provide means for the acquisition and/or recording of data in an appropriate and familiar mode to the student.

14. Use tag shapes for showing relationships (such as distance comparisons) buttons or other markers on a "layout" board.

15. A Braille label maker will be useful for identifying materials and containers in the laboratory for the vision impaired student who reads Braille.

16. Make equipment available that the vision impaired student can access in interpreting and understanding the results of laboratory exercises (e.g. audible readout voltmeters, calculators, talking thermometers, talking compass, magnifiers, etc.

17. Use a hot plate for heating instead of bunsen burner.

18. Label material, supplies, and equipment with regular print, large print, and/or Braille, as appropriate for the vision impaired student.

19. Pair the vision impaired student with a sighted student. Then have the non-impaired student describe the activities and outcomes as they are observed.

20. A low vision projection screen can be use to magnify images up to $720 \mathrm{X}$.

21. Use a portable communication board to provide auditory scanning of laboratory materials such as: pictographic symbols, letters, and/or words.

22. When using a computer, the student with a vision disability can use a voice input device or a remote voice system to verbally enter commands.

23. Prior to enrollment of a visually impaired student in class, obtain laboratory equipment that have adaptive outputs such as: a large screen, print materials, or various audio output devices.

24. Various braille devices can be used to assists vision impaired students when reading.

25. For "reading" the outputs of balances and other instruments, one can use a Braille N' Speak device (Blazie Engineering)

\section{Group Interaction and Discussion}

1. Describe and tactually/spatially familiarize the student to the classroom.

2. Place the student and/or recorder an appropriate distance from the activity to permit recording of material.

3. Use a tape recorder.

4. If the student is partially sighted, be sure he/she is seated where lighting is appropriate.

5. Use a note taker who takes notes in the appropriate mode. 


\section{VI. $\quad$ Reading}

1. Paid or volunteer readers or writers can assist a visually impaired student with texts, materials, and library readings.

2. Offer to read, or arrange to have read, written information for a person with a visual impairment, when appropriate.

3. Arrange, ahead of time, for audio book acquisition of the text or other reading materials through the Talking Book Service, Recordings for the Blind and Dyslexic , text reading systems, or audio output devices.

4. Various braille devices can be used to assists vision impaired students when reading.

\section{Field Experience}

1. Make all handouts, safety information and assignments available in an appropriate form (e.g., regular print, large print, Braille, or cassette).

2. Consider alternate activities/exercises that can be utilized with less difficulty for the student, but has the same or similar learning objectives.

3. Use a sighted guide.

4. Do detailed description and narration of objects seen in science centers, museums, and/or field activities.

5. The use of a laser cane or mowat sensor can be useful in assisting the student in unfamiliar surroundings.

6. An enlarged activity script, directions, or readings for descriptions of a field/activity for a low vision person to use with field observations.

7. Suggest that the student use a tape recorder.

\section{Research}

1. Review and discuss with the student the steps involved in a research activity. Think about which step(s) may be difficult for the specific functional limitations of the student and jointly devise accommodations for that student.

2. Use appropriate lab and field strategies according to the nature of the research.

3. Various Braille Devices can be used to assists vision impaired students when reading.

4. Suggest that the student use a tape recorder with a sighted person on the various activities.

\section{Testing}

1. Make arrangements for tactile examinations, if touch is not normally permitted (e.g., with a museum curator for access to a museum display item or for access to a plant/animal species collection).

2. Place the student being tested close to the activity if tactile examination is necessary.

3. Present examinations in a form that will be unbiased to visually impaired students. Ask the student for the approach he/she finds to be most accessible.

4. One possible accessible method is to record test questions on tape and have the students record their answers on tape.

5. Use an enlarged activity script, directions, or readings to go along with the testing material.

6. Allow more time.

7. Various and appropriate calculators can be used during the test.

\section{Research Methodology:}

\section{X. $\quad$ Research Methodology And Locale Of The Study}

In this present study, the Case Study Approach is adopted for undertaking extensive study of a concerned person, concerned social groups, an event, a process, a situation, a community and also all other social units concerned for the study. In this study, efforts are made to understand the life cycle of the concerned unit under study. With the help of case study method attempts are also made to get an intuition into the extreme case whose unique features are not reflected by the usual statistical methods. At the same time, Analytical Approach is also adopted in this study for specifying and interpreting the relationships.

\section{Research Design:}

Difficulty in accessibility of appropriate statistical information on aspects of social life as well as on the diverse strata of the society has made the task of research very arduous. It is enumerated and the following categories of persons/personnel as the universe for this research work are considered after careful examination and discussion.

- The concerned educational Institution.

- Head of the Institute.

- All the governing council members in educational Organisation.

- The professionals like teachers in the Maheshwari Blind School.

- $\quad$ All the officers of education departments. 
The total number of 12 Staff members and 74 students of Maheshwari School for Blind, Belgaum are chosen as respondents for the present study.

\section{Selection of Respondents:}

After resolving the nature and the respondents for this research work, information is compiled through wellprocessed questionnaires and various government offices and other organisations were contacted to get the information concerning Blind Schools working in distinct fields.

The departments approached for this purpose is:

$\Rightarrow$ Educational Institutions.

$\Rightarrow$ Government offices

$\Rightarrow$ Social organisations in the district.

$\Rightarrow$ Personal contacts.

In the current study inclusively 12 Staff members and 74 students of Maheshwari Blind School, Belgaum is chosen as respondents for the present study and is preferred for the collection of primary data.

\section{Source of Data:}

This study is based on both primary and secondary data. Primary data was collected with the help of the preordained closed-ended questionnaire, circulated \& canvassed to the respondents.

The Secondary data is collected from varied sources such as records of Panchayat, Zilla Panchayat office, Blind School institutions, personal contacts, through friends, reports, published articles, thesis in the book form, and other published literature pertaining to teachers and inmates of Blind School.

\section{Research Techniques and Tools Used:}

The primary and secondary data collected are analyzed and interpreted by using simple statistical tools viz. percentages, and tabular methods.

\section{Field Work:}

Fieldwork was guided by personally going over to the Belgaum district and visiting the various Departments and offices during February 2011 to April 2011 to collect the primary data. On this intensive personal discussion with the respondents was also made to gather the information.

\section{Processing and Analysing of Data:}

The data collected was fed in to the personal computer for processing and analysing the data and to draw the conclusions on the basis of the investigation.

\section{LOCALE OF THE STUDY}

Area:

The study area is located in the northwestern part of Karnataka State and falls within northern maiden region. The Belgaum district (named after its Head Quarters - Belgaum) extends between $15.23^{\circ}$ and $16.58^{\circ}$ north latitude and $75.5^{\circ}$ and $75.8^{\circ}$ east longitude. Dharwad and Uttar Kannada districts bound the district in the north by Sangli and Kolhapur districts and on the west by parts of Kolhapur and Ratnagiri of Maharashtra State and Goa on the east by Bijapur district in the South.

As per the 2001 census, Belgaum district's population is about 4,207.264 persons, out of which 2,147,746 male and 2,059,518 female populations and in 2001 the density of population was about 314 persons per sq.km.

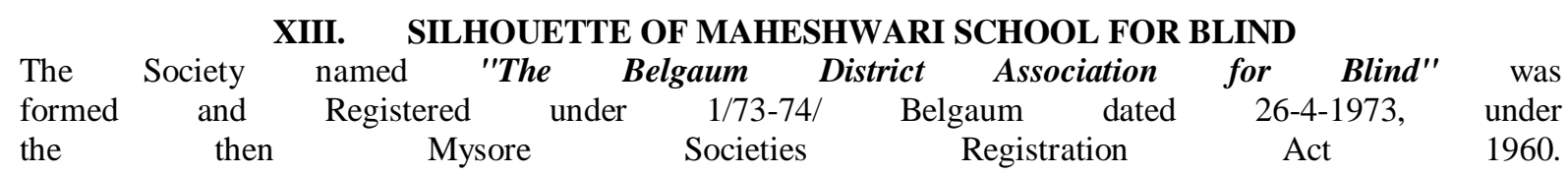

The main objective of the Society is to look after the welfare of the Blind and to educate them etc. The society is member of the National Association for the Blind, Mumbai.

\section{Infrastructure:}

The Association is running a full-fledged Residential school from I to Xth Std for the Blind boys and girls. The Association is having its own a one Stored building constructed in the 1987 on its own site donated by the City Corporation .For the present there are 120 Students including 70 boys and 50 girls studying in the school and 12 no. of specially trained teachers are teaching them. Free boarding, lodging, bedding, clothing, medical care facilities are provided and every students care is being taken in all respects by every teacher and the members of the Association. 
Academic Activities:

The Maheshwari School for Blind is started on the auspicious day of Gandhi Jayanthi 1978, has just entered the Silver Jubilee year. The school has been adjudged by the Government of Karnataka as the best school and awarded a cash prize of Rs. 15,00.00 in the year 1996.In addition to this the school gets cent percent results in the SSLC Examination every year. All examination from the various Institutions will get through the examinations.

\section{Co-curricular Activities:}

Kumar Basavraj Umarani studying in 3rd std., will tell the day and date of any year that is asked without referring to anything and this is appreciated by all including the Raj Pramhukh and the some ministers of the Government of Karnataka In addition to this boys and girls have participated in the sports events conducted by the Blind Relief Association and Indian Sports Association, New Delhi. Most of the students have got success in their events and received the awards. In addition to this three of the school has participated in chess competition conducted by the National Association for the Blind.

\section{Vocational Training}

Apart from education the students are trained in Music and vocational training such as basket making, rescanning of chairs, candle making etc.

\section{NEED AND IMPORTANCE OF THE STUDY:}

After independence many private organizations were established for the education of the disabled children. The government was interested in their education and a comprehensive countrywide survey of persons with disability revealed that approximately over 90 million people were suffering from one or the other kind of disability. It can be said that about 12 million people were suffering from blindness.

It is necessary to highlight and have an indepth analysis on methods of training blind children and implications of suitable research undertaking. The encouragement to research studies on the blind students shall help to find out how the so called Blind schools are performing their role and what are their short comes and success stories. This will not only enhance the quality of education but also lead to contribution of the disabled for national development.

\section{STATEMENT OF THE PROBLEM:}

The researcher as a teacher felt the importance to aware the parents of disabled children and the fact that their children can be educated and the parents can be informed about the facilities available for their children and enlighten them with necessary information leading to give an insight into the nature of work demanded from private organisation.

The present study "Enabling the disabled through Educational Amenities: A Sociological Analysis on Maheshwari School for Blind" aspire to reduces negative attitudes towards the disabled through the building of healthy social relationships between normal and disabled children.

\section{OBJECTIVES OF THE STUDY:}

1. To know the historical background of the Institution.

2. To analyse the basic facilities in the Institution.

3. Analyse the curriculum, methods of teaching and evaluation of the blind children.

4. To highlight the contribution of the institution towards blinds students in particular.

5. To explain the academic and non-academic functions of the institution.

6. To know the implementation of government provisions by the trust for students.

7. Illustrate the academic achievements of the students.

\section{METHODOLOGY:}

The study employs descriptive method where primary and secondary methods of data collection are used. The primary data is collected by personally contacting the Head of the Institute, Teachers, Students and the Governing council members.

Secondary data is collected by referring various books, articles, newspapers, government orders, gazette, and records of government department, published and unpublished thesis to have an in-depth analysis on the relevant topic.

\section{TOOLS AND TECHNIQUES:}


With the help of pre-ordained questionnaire and interview schedule necessary information is collected by personally contacting the respondents and has a comprehensive discussion with the concerned to acquire reliable information.

The information collected by contacting the respondents through and indepth and extensive interview using the interview schedule is represented with the help of tabulation and charts with analytical elaboration and findings.

\section{REVIEW OF LITERATURE}

Firsthand (1994) "Beginning with Braille" Firsthand Experiences with a Balanced Approach to Literacy, from the American Foundation for the Blind, begins with a discussion of the whole language and traditional approaches to teaching reading and writing. Author Anna M. Swenson is a Braille teacher who favors the whole language philosophy, but who has taught in various settings, and includes ideas and techniques that will work with the traditional approach as well.

Scadden, L. A. (1996), "Making mathematics and science accessible to blind students through technology", Modern technology provides increased access to math and science educational instruction materials, media, and laboratory activities for blind students. Five projects supported by the National Science Foundation are described. One of these is a rigorous evaluation by the American Foundation for the blind (AFB) of the value of audio description of science programs, which featured more than 100 blind viewers. Results of the study clearly demonstrate that blind viewers understand and retain information from science videos far better when audio descriptions are provided.

Ruby Ryles(2004), 'Research Study: Early Braille Education Vital', An exhaustive study has cast aside some erroneous stereotypes while underscoring the importance of Braille education at an early age. The study has revealed that literacy rates of blind high school students who began their Braille education at an early age are consistent with those of their sighted peers. The study further disclosed that legally blind children who received infrequent or no Braille training, or who began their Braille education later in life, exhibit noticeably lower literacy rates.

Robinson, Denise (2006) "Learning strategies that enable blind students to access education", blind people have a problem being able to access print information. Therefore, the primary purpose of this study was to investigate whether particular learning strategies may enable the blind to gain more access to the print world through education and instruction. Since the blind are experiencing $80 \%$ illiteracy and $74 \%$ unemployment, an investigation into additional learning strategies that enable the blind to access more information and the printed word was prudent..

Hayhoe, Simon (2008) in "Arts, culture and blindness: studies of blind students in the visual arts". It is the first book to study adult and child art students actually participating in courses designed with their needs in mind in universities and schools for the blind. In doing so it uniquely delves into the topic of the culture of education and society and its effects on an understanding of blindness and the visual arts.

\section{ANALYSIS AND INTREPRATATION OF DATA}

On the basis of the field work and comprehensive analysis, the respondents considered for the research task were the Head of the Institute, Teachers and the inmates i.e., the students studying in Maheshwari High School. The data collected from respondents is interpreted in totality, which is exclusive of separate interpretation in order to get the collective information and to avoid dispersed and inconsistent facts.

Table No. 1

Number of Staff in the School

\begin{tabular}{|c|l|c|}
\hline Sl.No & \multicolumn{1}{|c|}{ Staff } & No. of Staff Members \\
\hline 1. & Teaching & 12 \\
\hline 2. & Non-Teaching & 04 \\
\hline 3. & D-Grade & 06 \\
\hline \multicolumn{2}{|c|}{ Total } & 22 \\
\hline
\end{tabular}

Source : Field Survey

Table No. 1 reveals that there are 22 staff members in Maheshwari School for Blind, it comprises of 12 teachers, 4 clerical and 6 D-Grade Staff members. With the help of the given information it can be concluded that the school not only have a good number of staff members in teaching and non-teaching but it also shows that there is a separate teacher for each subject.

Table No. 2 
Number of Students in SSLC

\begin{tabular}{|l|c|c|}
\hline Sl.No & No of Students & Percentage \\
\hline Male & 11 & 78.57 \\
\hline Female & 03 & 21.43 \\
\hline Total & 14 & 100.00 \\
\hline
\end{tabular}

Source : Field Survey

The students are real strength of an Institute and the Table No. 2 exhibits that the SSLC classes have 14 students out of which 78.57 percent are male students and remaining 21.43 percent students are females. Here it can be derived that there is more enrolment of male as compared to females in Blind schools.

Table No. 3

Number of Students in IX

\begin{tabular}{|l|c|c|}
\hline Sl.No & No of Students & Percentage \\
\hline Male & 10 & 66.67 \\
\hline Female & 05 & 33.33 \\
\hline Total & 15 & 100.00 \\
\hline
\end{tabular}

Source : Field Survey

Out of total 15 students in Class IX Table No. 3 discloses that 66.67 percent of the students are male and 33.33 percent are females. Here also we can say that the strength of male students exceeds the females.

Table No. 4

Number of Students in VIII

\begin{tabular}{|l|c|c|}
\hline Sl.No & No of Students & Percentage \\
\hline Male & 12 & 75.00 \\
\hline Female & 04 & 25.00 \\
\hline Total & 16 & 100.0 \\
\hline
\end{tabular}

Source : Field Survey

Table No. 4 informs that out of 16 students in Class VIII 75 percent of the students are male and remaining 25 percent are females. Here it can be deduced that majority of the students in Maheshwari Blind School are males.

Table No. 5

Number of Students in VII

\begin{tabular}{|c|c|c|}
\hline Sl.No & No of Students & Percentage \\
\hline Male & 08 & 61.54 \\
\hline Female & 05 & 38.46 \\
\hline Total & 13 & 100.0 \\
\hline
\end{tabular}

Source : Field Survey

It is observed that Class VII have less students i.e., 13 students and here also majority of the students are male as compared to female. 61.54 percent of the student studying in Class VII are males and 38.46 percent are males.

Table No. 6

Number of Students in VI

\begin{tabular}{|l|c|c|}
\hline Sl.No & No of Students & Percentage \\
\hline Male & 11 & 68.75 \\
\hline Female & 05 & 31.25 \\
\hline Total & 16 & 100.0 \\
\hline
\end{tabular}

Source : Field Survey

The number of students in Maheshwari School for Blind is increasing every year and Table No. 6 discloses the fact. Out of total 16 students 68.75 percent of the students are male and remaining 31.25 percent are females.

Table No. 7

Basic Infrastructure and Resources for Educational Development 
Enabling The Disabled Through Educational Amenities: A Sociological Analysis On Maheshwari

\begin{tabular}{|c|c|c|}
\hline $\begin{array}{l}\text { Sl } \\
\text { No }\end{array}$ & Resources & Number and Nature \\
\hline 1. & Building & Planned \\
\hline 2. & Furniture & Just Furnished \\
\hline 3. & Staff Room & Well Furnished \\
\hline 5. & $\begin{array}{l}\text { Library } \\
\text { No. of Books }\end{array}$ & $\begin{array}{c}\text { Yes } \\
\text { 400(Braile, Story \& Moral Education) }\end{array}$ \\
\hline 6. & $\begin{array}{l}\text { Audio Visual Equipments } \\
\text { Nature of A.V. Equipments }\end{array}$ & $\begin{array}{c}\text { Yes } \\
\text { Radio, Tape Record, Cassettes }\end{array}$ \\
\hline 7. & $\begin{array}{l}\text { Water Facility } \\
\text { Nature of Water Facility }\end{array}$ & $\begin{array}{c}\text { Yes } \\
24 \text { Hours } \\
\end{array}$ \\
\hline 8. & Nature of Electric Facility & Regular \\
\hline 9. & \begin{tabular}{ll}
\multicolumn{2}{l}{ Sanitation Facility } \\
i. & No. of Urinals \\
ii. & No. of Toilets \\
iii. & No. of Bathrooms
\end{tabular} & $\begin{array}{l}07 \\
05 \\
12\end{array}$ \\
\hline 10. & $\begin{array}{l}\text { Medical Check-up } \\
\text { How often? }\end{array}$ & $\begin{array}{c}\text { Regular } \\
\text { Twice in an Year }\end{array}$ \\
\hline 11. & Provision of Uniform & Yes \\
\hline 12. & $\begin{array}{l}\text { No. of Rooms in Hostel } \\
\text { No. of Beds in Each Room }\end{array}$ & $\begin{array}{l}08 \\
15 \\
\end{array}$ \\
\hline 14. & $\begin{array}{l}\text { Playground Facility } \\
\text { Area of Playground }\end{array}$ & $\begin{array}{c}\text { Yes } \\
3 \text { Acres \& } 8 \text { Guntas }\end{array}$ \\
\hline 15. & Available sports materials & $\begin{array}{c}\text { Chess Board } \\
\text { Cricket Kit } \\
\text { Athletics } \\
\text { Volley Ball } \\
\text { Throw Ball } \\
\text { Lezims } \\
\text { Dumbles } \\
\text { Skipping Ropes } \\
\end{array}$ \\
\hline 16. & $\begin{array}{l}\text { Conducting of Sports Activities } \\
\text { Type of Sports }\end{array}$ & $\begin{array}{c}\text { Yes } \\
\text { Chess } \\
\text { Carrom } \\
\text { Athletics } \\
\text { Long Jump } \\
\end{array}$ \\
\hline
\end{tabular}

Source : Field Survey

Infrastructure: The building of Maheshwari blind school is well planned and has all the basic requirements. The furniture in staff room is well furnished and other furniture used is just furnished. The school have spacious library with 400 books which includes Braille, Story and Moral Education books and have radio, tape record, DVD \& VCD cassettes and cassettes players as audio-video equipments and also computers.

The school has regular and 24 hour water and electric facility. The school is very much concerned about the sanitation and has 7 urinals, 5 toilets and 12 bathrooms. The students are provided Uniform and hostel, hostel has 8 rooms and each room has 15 beds.

The Institute always follow the principle of 'healthy body healthy mind', the school have a huge play ground and the inmates are given time to play and generate enthusiasm and zeal for sports and games they have sports materials like Chess Board, Cricket Kit, Athletics, Volley Ball, Throw Ball, Lezims, Dumbles, Skipping Ropes etc., and thus alongwith the games the health of the students is maintained and the school have provision of medical check-ups twice in an year for all the inmates.

\section{A. AMENITIES:}

1. Communication : The Maheshwari Blind School have Telephone, and Internet Service for communication, this shows that the school not only have the regular source of communication but also have modern technology such as internet as a medium for communication. 
Enabling The Disabled Through Educational Amenities: A Sociological Analysis On Maheshwari

2. Class Rooms: The basic facility like the classroom plays and important role in imparting education. Here the school runs 5 classes and have 10 classrooms, which shows that the school not only has excess rooms but also spacious rooms, enabling better education. The highly appealing aspects is the school not only have class rooms but also separate rooms for Yoga, Gymnastics, Music and Craft room.

\section{B. Curriculum - Teaching AND Evaluation:}

1. Curriculum Activities: The curriculum activities involves regular class, seminars, debates, group discussion

2. Instructional material: Braille slates, Braille Maps, Teaching Aids, Geometric Braille

3. Extracurricular activities: Excursions, Games, Cultural activities and open competitions

1. Innovative Practices: Supervised study, Grouping (for teaching activities), Enrichment programmes, Computer Education.

2. Moral Education: The development of self is possible only if there is spiritual development. The moral education given in Maheshwari Blind School develops the inner-self and thus it enables and encourages them to face the difficulties of life with peaceful soul.

\section{FINANCIAL MANAGEMENT OF MAHESHWARI BLIND SCHOOL:}

The expenses of the School are met by generous donations and grants from Karnataka State Government. The main reason behind the satisfactory infrastructure and basic facilities is also due to the support and encouragement by the state government and the generous donors. The inmates are given all the necessary facilities without taking any fee or donation from the students i.e., the school is providing free education to the blind students.

\section{SCHOOL COMMUNITY RELATIONSHIP:}

To enrich the quality of education and social relation, the Maheshwari Blind School conducts regular parent-teacher meet and welcomes their ideas and suggestions with open heart. Here, it's really appreciable that not only the parents and teachers but the school betterment committee is very much concerned and particular about the standard to education and for this the school betterment committee visits the school regularly.

The research also acknowledges that the school celebrates almost all the festivals and activities and school functions altogether, this is not only a source of recreation and amusement for the students, but on the other hand the school have maintained the tradition and culture of Indian Society.

\section{E. ACADEMIC ACHIEVEMENTS:}

Table No. 8

SSLC Results of past five year

\begin{tabular}{|c|l|c|c|}
\hline \multirow{4}{*}{$\begin{array}{c}\text { Year } \\
2010\end{array}$} & Class Obtained & No. of Students & Percentage \\
\cline { 2 - 4 } & I Class & 03 & 23.07 \\
\cline { 2 - 4 } & II Class & 00 & 00.00 \\
\cline { 2 - 4 } & III Class & 00 & 00.00 \\
\cline { 2 - 4 } & Distinction & 10 & 76.93 \\
\cline { 2 - 4 } & Failed & 00 & 00.00 \\
\hline & Total & 13 & 100.00 \\
\hline
\end{tabular}

Source : Field Survey

The success and failure and the quality of education can be very much understood by the annual result of the students. Table No. 8 shows that, 23 percent of the students have received I Class and 76.93 percent have got Distinction in their examination in the year 2010. Most of the students have passed their SSLC examination with distinction, which shows that the academic achievement of Maheshwari is far above the normal. This shows the quality of education received by the students in the school.

Table No. 9

SSLC Results of past five year

\begin{tabular}{|c|l|c|c|}
\hline \multirow{3}{*}{$\begin{array}{c}\text { Year } \\
2009\end{array}$} & Class Obtained & No. of Students & Percentage \\
\cline { 2 - 4 } & I Class & 06 & 37.50 \\
\cline { 2 - 4 } & II Class & 04 & 25.00 \\
\cline { 2 - 4 } & III Class & 00 & 00.00 \\
\hline
\end{tabular}


Enabling The Disabled Through Educational Amenities: A Sociological Analysis On Maheshwari

\begin{tabular}{|l|l|c|c|}
\hline & Distinction & 06 & 37.50 \\
\cline { 2 - 4 } & Failed & 00 & 00.00 \\
\hline & Total & 16 & 100.00 \\
\hline
\end{tabular}

\section{Source : Field Survey}

Table No. 9 exhibits that 37.50 percent of the students have received I Class, 25 percent II Class and remaining 37.50 percent have taken Distinction. From the above table it is understood that majority of the students have taken either I Class or Distinction.

Table No. 10

SSLC Results of past five year

\begin{tabular}{|c|l|c|c|}
\hline \multirow{4}{*}{$\begin{array}{c}\text { Year } \\
2008\end{array}$} & Class Obtained & No. of Students & Percentage \\
\cline { 2 - 4 } & I Class & 05 & 41.67 \\
\cline { 2 - 4 } & II Class & 00 & 00.00 \\
\cline { 2 - 4 } & III Class & 00 & 00.00 \\
\cline { 2 - 4 } & Distinction & 07 & 58.33 \\
\cline { 2 - 4 } & Failed & 00 & 00.00 \\
\hline & Total & 12 & 100.00 \\
\hline
\end{tabular}

Source : Field Survey

The Board Exam of SSLC in 2008 was very favourable for the students of Maheshwari Blind School. 41.67 percent of the students have received I Class and 58.33 percent have passed with Distinction. The majority of Distinction holder and 100 percent passing result in 2008 is a mirror for the success of Maheshwari School

Table No. 11

SSLC Results of past five year

\begin{tabular}{|c|l|c|c|}
\hline \multirow{5}{*}{ Year } & Class Obtained & No. of Students & Percentage \\
\cline { 2 - 4 } 2007 & I Class & 04 & 50.00 \\
\cline { 2 - 4 } & II Class & 00 & 00.00 \\
\cline { 2 - 4 } & III Class & 00 & 00.00 \\
\cline { 2 - 4 } & Distinction & 04 & 50.00 \\
\cline { 2 - 4 } & Failed & 00 & 00.00 \\
\hline & Total & 08 & 100.00 \\
\hline
\end{tabular}

Source : Field Survey

In the year 2007 the school produced 100 percent result. Out of total 8 students 50 percent have got I Class and the similar percentage of student has attained Distinction.

Table No. 12

SSLC Results of past five year

\begin{tabular}{|c|l|l|l|}
\hline \multirow{5}{*}{$\begin{array}{c}\text { Year } \\
2006\end{array}$} & Class Obtained & No. of Students & Percentage \\
\cline { 2 - 4 } & I Class & 05 & 55.56 \\
\cline { 2 - 4 } & II Class & 02 & 22.22 \\
\cline { 2 - 4 } & III Class & 00 & 00.00 \\
\cline { 2 - 4 } & Distinction & 02 & 22.22 \\
\cline { 2 - 4 } & Failed & 00 & 00.00 \\
\hline & Total & 09 & 100.00 \\
\hline
\end{tabular}

Source : Field Survey

Five year back i.e., in 2006 though the numbers of student in SSLC were less but the school produced 100 percent result. 55.56 percent had attained I Class, 22.22 percent II Class and remaining 22.22 percent have taken Distinction.

On the basis of academic achievements of the students and the rise in the admission in Maheshwari Blind School prove the fact that the quality of education is beyond one's comparison and here the role of teachers in each a every aspects of school life can we seen and observed. It won't be wrong to say that, there is a great role of teachers in enabling the disabled children.

The academic, cultural, sports, recreational and religious activities and 100 percent SSLC results of the students studying in Maheshwari Blind school is very much contributed by the Teachers and Maheshwari Blind 
School stands as an ideal to the fact that, a teacher can change the present and future of a student, whether able or disable.

\section{COMPOSITION OF STAFF \& STUDENTS}

\section{FINDINGS}

- There are 22 staff members in Maheshwar School for Blind, it comprises of 12 teachers, 4 clerical and 6 D-Grade Staff members. The school has a good number of staff members in teaching and non-teaching and there is a separate teacher for each subject.

\section{Number of Students}

- Number of Students in SSLC: The students are the real strength of an Institute and it exhibits that the SSLC class have 14 students out of which 78.57 percent are male students and remaining 21.43 percent students are females. Here it can be derived that there is more enrolment of male as compared to females in Blind schools.

- Number of Students in IX: Out of total 15 students in Class IX 66.67 percent of the students are male and 33.33 percent are females. Here also we can say that the strength of male students exceeds the females.

- Number of Students in VIII: Out of 16 students in Class VIII 75 percent of the students are male and remaining 25 percent are females. Here it can be deduced that majority of the students in Maheshwari Blind School are males.

- Number of Students in VII: It is observed that Class VII have less students i.e., 13 students and here also majority of the students are male as compared to female. 61.54 percent of the student studying in Class VII are males and 38.46 percent are males.

- Number of Students in VI: The number of students in Maheshwari School for Blind is increasing every year and it discloses the fact that, out of total 16 students 68.75 percent of the students are male and remaining 31.25 percent are females.

\section{Infrastructure:}

- The building of Maheshwari blind school is well planned and has all the basic requirements. The furniture in staff room is well furnished and other furniture used is just furnished. The school have spacious library with 400 books which includes Braille, Story and Moral Education books and have radio, tape record, DVD \& VCD cassettes and cassettes players as audio-video equipments and also computers.

The school has regular and 24 hour water and electric facility. The school is very much concerned about the sanitation and has 7 urinals, 5 toilets and 12 bathrooms. The students are provided Uniform and hostel, hostel has 8 rooms and each room has 15 beds.

- The Institute always follow the principle of 'healthy body healthy mind', the school have a huge play ground and the inmates are given time to play and generate enthusiasm and zeal for sports and games they have sports materials like Chess Board, Cricket Kit, Athletics, Volley Ball, Throw Ball, Lezims, Dumbles, Skipping Ropes etc., and thus alongwith the games the health of the students is maintained and the school have provision of medical check-ups twice in an year for all the inmates.

\section{AMENITIES:}

- Communication : The Maheshwari Blind School have Telephone, and Internet Service for communication, this shows that the school not only have the regular source of communication but also have modern technology such as internet as a medium for communication.

- Class Rooms: The basic facility like the classroom plays an important role in imparting education. Here the school runs 5 classes and have 10 classrooms, which shows that the school not only has excess rooms but also spacious rooms, enabling better education.

The highly appealing aspects is the school not only have class rooms but also separate rooms for Yoga, Gymnastics, Music and Craft room.

\section{Curriculum - Teaching and Evaluation:}

- Curriculum Activities: The curriculum activities involves regular class, seminars, debates, group discussion

- Instructional material: Braille slates, Braille Maps, Teaching Aids, Geometric Braille

- Extracurricular activities: Excursions, Games, Cultural activities and open competitions

- Innovative Practices: Supervised study, Grouping(for teaching activities), Enrichment programmes, Computer Education.

- Moral Education: The development of self is possible only if there is spiritual development. The moral education given in Maheshwari Blind School develops the inner-self and thus it enables and encourage them to face the difficulties of life with peaceful soul. 

FINANCIAL MANAGEMENT OF MAHESHWARI BLIND SCHOOL:

The expenses of the School are met by generous donations and grants from Karnataka State Government. The main reason behind the satisfactory infrastructure and basic facilities is also due to the support and encouragement by the state government and the generous donors. The inmates are given all the necessary facilities without taking any fee or donation from the students i.e., the school is providing free education to the blind students.

\section{SCHOOL COMMUNITY RELATIONSHIP:}

To enrich the quality of education and social relation, the Maheshwari Blind School conducts regular parent-teacher meet and welcomes their ideas and suggestions with open heart. Here, it's really appreciable that not only the parents and teachers but the school betterment committee is very much concerned and particular about the standard to education and for this the school betterment committee visits the school regularly.

\section{ACADEMIC ACHIEVEMENTS:}

- $\quad$ The success and failure and the quality of education can be very much understood by the annual result of the students, heret 23 percent of the students have received I Class and 76.93 percent have got Distinction in their examination in the year 2010. Most of the students have passed their SSLC examination with distinction, which shows that the academic achievement of Maheshwari is far above the normal. This shows the quality of education received by the students in the school. .

- In 200937.50 percent of the students have received I Class, 25 percent II Class and remaining 37.50 percent have taken Distinction. From the above table it is understood that majority of the students have taken either I Class or Distinction.

- The Board Exam of SSLC in 2008 was very favorable for the students of Maheshwari Blind School. 41.67 percent of the students have received I Class and 58.33 percent have passed with Distinction. The majority of Distinction holder and 100 percent passings result in 2008 is a mirror for the success of Maheshwari School

- In the year 2007 the school produced 100 percent result. Out of total 8 students 50 percent have got I Class and the similar percentage of student has attained Distinction.

- In 2006 though the number of students in SSLC were less but the school produced 100 percent result. 55.56 percent had attained I Class, 22.22 percent II Class and remaining 22.22 percent have taken Distinction.

On the basis of academic achievements of the students and the rise in the admission in Maheshwari Blind School prove the fact that the quality of education is beyond one's comparison and here the role of teachers in each a every aspects of school life can we seen and observed. It won't be wrong to say that, there is a great role of teachers in enabling the disabled children.

The academic, cultural, sports, recreational and religious activities and 100 percent SSLC results of the students studying in Maheshwari Blind school is very much contributed by the Teachers and Maheshwari Blind School stands as an ideal to the fact that, a teacher can change the present and future of a student, whether able or disable.

\section{BIBLIOGRAPHY}

[1.] Chintamanikar, "Exceptional Children their Psychology and Education", Sterling Publishers Pvt Ltd, 1994

[2.] Jagannatha Mohnthya, "Human Rights Education”, Deep and Deep Publications Pvt. Ltd, New Delhi, 2000

[3.] Lydia Fernandes, Anandi, A.Shashikala, "Trends In Modern Education", Vijaylakshmi Prakashna, Mysore, 2003

[4.] Panda K.C., "Education of Exceptional Children", Vikas Publishing House, New Delhi, 1997

[5.] Saha B.K. "Education of Exceptional", Kalyani Publication, New Delhi, 1993

[6.] Hayhoe, Simon "Arts, culture and blindness: studies of blind students in the visual arts”. Cambria Press, Youngstown, 2008

[7.] Ruby Ryles "Research Study: Early Braille Education Vital”, The Spring, edition of HumanWare's publication,1998

[8.] International Council of Ophthalmology. "International Standards: Visual Standards — Aspects and Ranges of Vision Loss with Emphasis on Population Surveys." April 2002.

[9.] Koestler, F. A. "The unseen minority: a social history of blindness in the United States". New York: David McKay, 1976

[10.] Al-Merjan, JI; Pandova, MG; Al-Ghanim, M; Al-Wayel, A; Al-Mutairi, S, "Registered blindness and low vision in Kuwait". Ophthalmic epidemiology 12 (4): 251-7. doi: PMID 16033746.2005

[11.] "Identification and notification of sight loss" Retrieved April 26, 2010.

[12.] "Certificate of Vision Impairment: Explanatory Notes for Consultant Ophthalmologists and Hospital Eye Clinic Staff" retrieved April 26, 2010.

[13.] Bunce, C; Wormald, R. "Leading causes of certification for blindness and partial sight in England \& Wales". BMC public health 6: 58. doi:10.1186/1471-2458-6-58. PMC 1420283. PMID 16524463, 2006.

[14.] American Foundation for the Blind. "Statistics and Sources for Professionals." Retrieved April 1, 2006.

[15.] Punani, Dr. Bhushan, "Effective Use of Information and Communication", October 2000.

[16.] Technology for Physically and Socially Disadvantaged Groups." Chapter 12 in Subhash Bhatnagar and Robert Schware, eds., Information and Communication, 2003

[17.] Technology in Rural Development: Case Studies from India. Washington D.C, 2007.

[18.] Punani, Dr. Bhushan, and Nandini Raval Jagdish Patel: The Visionary. Ahmedabad India: Blind Men's Association, 1997.

[19.] Punani, Dr. Bhushan, and Nandini Raval. Visual Impairment Handbook. Ahmedabad India,:Blind People's Association, 2000 